\title{
THE IMPORTANCE OF CHROMITE MORPHOLOGY IN DIAMOND EXPLORATION.
}

\author{
Dearn C. Lee ${ }^{* 1}$, Jess Maddren ${ }^{2}$, Brendan J. Griffin ${ }^{2}$ \\ ${ }^{1}$ Western Australia. ${ }^{2}$ The University of Western Australia, Australia 6009
}

\section{INTRODUCTION}

Exploration for kimberlite and lamproite is usually carried out by stream sediment sampling surveys followed by a search of the heavy-mineral concentrates from the samples by microscope observation. The microscope search is normally for the most important indicator minerals: pyrope garnet, magnesian ilmenite and chromite. Other minerals derived from kimberlite such as chrome diopside, pyroxenes, olivine, zircon and moissanite are frequently weathered to destruction at or close to source or occur in such small quantities that they do not form significant trails that can be followed by stream sampling.

Pyrope garnet and chromites have a direct association with diamond as they both may occur in diamond bearing rocks at depth in the earths' mantle and can appear at the surface of the earth in kimberlites and lamproites. Pyrope and chromite are therefore the most important minerals to look for in a search for diamond bearing kimberlites and lamproites. In many instances, weathering destroys pyrope garnet and the only indicator mineral remaining in quantity to form a dispersion trail is chromite. It is therefore of vital importance that chromites derived from kimberlite or lamproite be recognized if they occur in exploration samples. While colour and chemistry can be used to easily identify pyrope garnets, the equally important chromite mineral can be confused with chromites derived from many common rock types. In diamond exploration, methods for distinguishing between common chromites and chromites that are derived from kimberlite and lamproite must rely heavily on chromite morphology and surface textures. The Chemical composition of chromites can be used in some instances but in general this is less reliable than morphology and surface textures for distinguishing between common and kimberlitic chromites. The huge numbers of common chromites that are frequently encountered during exploration also make chemical analysis of individual chromites a highly impractical tool.

\section{SAMPLES AND METHODS}

Samples of chromites were obtained from diamond bearing kimberlites and lamproites in Australia, Canada, India, South Africa and Russia. Samples in most cases consisted of from 100 to 1000 individual chromite macrocrysts in the size range from $0.3 \mathrm{~mm}$ to $1.2 \mathrm{~mm}$. Samples of chromites from common source rocks such as peridotites, basalts, mafics and ultra-mafics in Australia were also obtained and one sample from a monchiquite. The chromite samples were examined by binocular microscope to determine overall morphologies. A Philips XL30 variable pressure scanning electron microscope (SEM) was used to examine surface features and obtain backscatter images. A JEOL 6400 SEM with standardized energy dispersive spectrometer was used for chemical analysis and x-ray mapping and a JEOL 3000F field emission transmission electron microscope was used to examine internal chromite structures.

\section{CHROMITE MORPHOLOGIES}

The chromites were classified into four groups: octahedral, truncated octahedral, flattened with low elongation and high elongation. Examples of each class are depicted in Figure 1. The octahedron is the normal chromite growth form while the truncated octahedral shape is derived from the break up of twinned crystals or aggregates of crystals. The flattened/low elongation group are distorted octahedrons that have a squashed appearance with length and breadth exceeding the height. In this group, length often exceeds the width and the grains appear elongated. The high elongation group have a length to width ratio of $1.75: 1$ or more and a distinct appearance of elongation. The results of this classification are shown in Table 1. Well-shaped octahedrons and truncated octahedrons are rare in the samples from kimberlites but they are the dominant forms in the common chromite samples. The chromites from kimberlite and diamond bearing lamproites include a high proportion of distorted octahedrons often with some elongation and a significant proportion with high elongation. Chromites with the high elongation classification are virtually absent from the common chromite samples. 


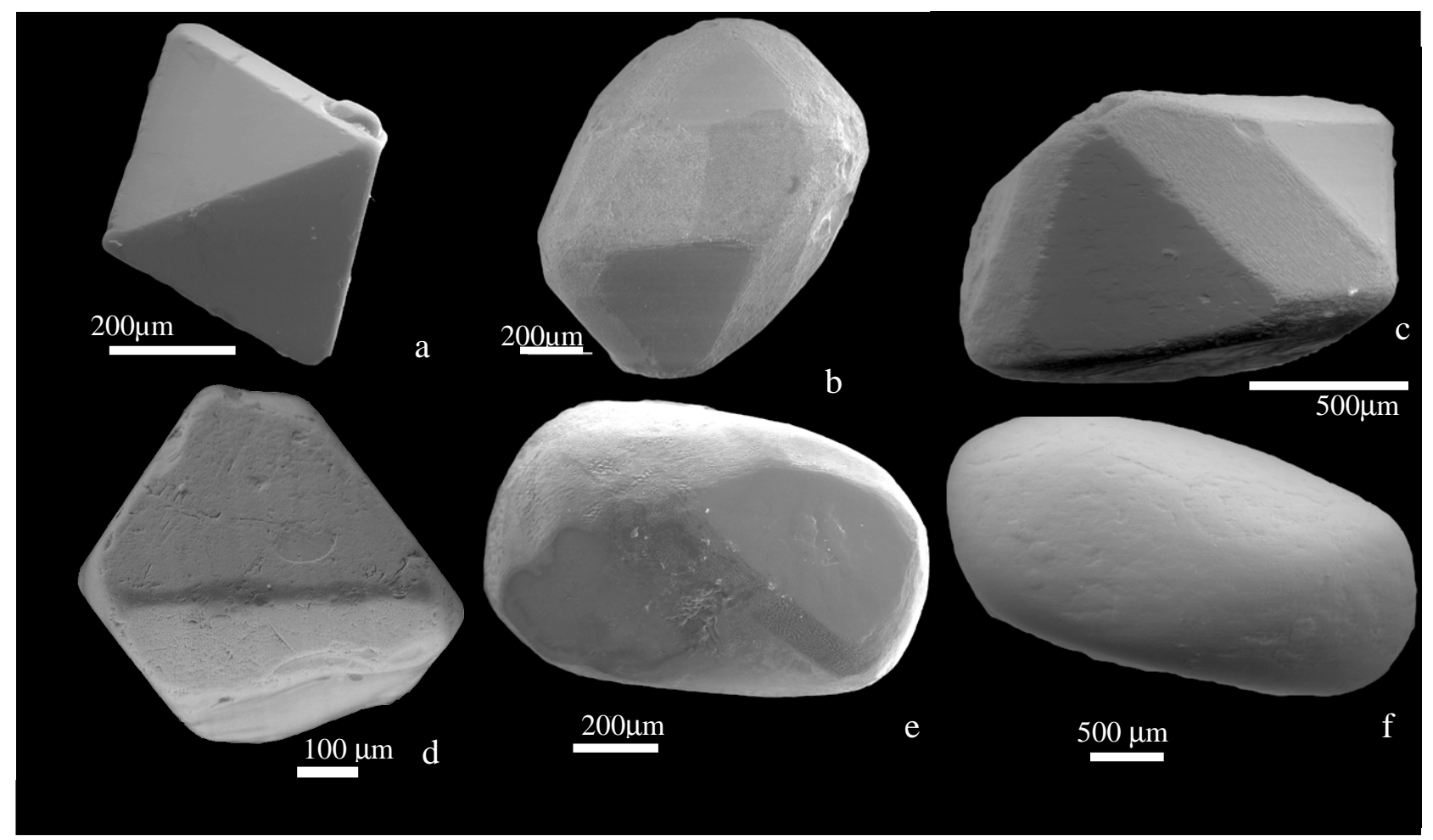

Figure 1: SEM photomicrographs of chromite grains representing the four classification groups used in this study, a) octahedral, d) truncated, b) and e) flattened/elongate, c) and f) high elongation.

Table 1: Population percentages of chromite morphology classified using an optical microscope and defined classes.

\begin{tabular}{|c|c|c|c|c|c|c|c|}
\hline Sample Locality & Rock Type & $\begin{array}{c}\text { Country of } \\
\text { Origin }\end{array}$ & $\begin{array}{c}\text { Total No. } \\
\text { of Samples }\end{array}$ & Octahedral & $\begin{array}{l}\text { Truncated } \\
\text { Octahedral }\end{array}$ & $\begin{array}{c}\text { Flattened/ } \\
\text { Low } \\
\text { Elongation }\end{array}$ & $\begin{array}{c}\text { High } \\
\text { Elongation }\end{array}$ \\
\hline Ellendale & Lamproite & Australia & 1161 & 1.55 & 0.69 & 86.91 & 10.85 \\
\hline Ekati Pipe 1 & Kimberlite & Canada & 132 & 0.76 & 0.76 & 91.67 & 6.82 \\
\hline Ekati Pipe 2 & Kimberlite & Canada & 273 & 1.83 & 0.73 & 89.01 & 8.42 \\
\hline Raipur & Kimberlite & India & 502 & 1.59 & 1.00 & 86.45 & 10.96 \\
\hline Crown/Lace & Kimberlite & South Africa & 127 & 3.94 & 1.57 & 88.98 & 5.51 \\
\hline Dokolwayo & Kimberlite & South Africa & 247 & 0.40 & 0.40 & 91.09 & 8.10 \\
\hline Kosmos & Kimberlite & South Africa & 187 & 0.53 & 0.00 & 88.24 & 11.23 \\
\hline Karevlei & Kimberlite & South Africa & 424 & 0.71 & 0.24 & 77.12 & 21.93 \\
\hline Roberts Victor & Kimberlite & South Africa & 80 & 2.50 & 1.25 & 68.75 & 27.50 \\
\hline Arkhangelsk & Kimberlite & Russia & 115 & 2.61 & 1.74 & 89.57 & 6.09 \\
\hline Aikhal & Kimberlite & Russia & 19 & 0.00 & 10.53 & 63.16 & 26.32 \\
\hline 23rd Congress & Kimberlite & Russia & 66 & 1.52 & 4.55 & 74.24 & 19.70 \\
\hline Tasmania & Peridotite & Australia & 1231 & 86.19 & 8.85 & 4.63 & 0.32 \\
\hline Antrim & Volcanic & Australia & 99 & 54.55 & 12.12 & 33.33 & 0.00 \\
\hline Turton Creek & $\begin{array}{l}\text { Intermediate } \\
\text { to Ultramafics }\end{array}$ & Australia & 1188 & 3.11 & 94.02 & 2.27 & 0.59 \\
\hline Kimberley & $\begin{array}{c}\text { Carson } \\
\text { Volcanic }\end{array}$ & Australia & 55 & 1.82 & 85.45 & 12.73 & 0.00 \\
\hline Kambalda Dome & $\begin{array}{c}\text { Mafics/ } \\
\text { Ultramafics }\end{array}$ & Australia & 53 & 28.30 & 52.83 & 18.87 & 0.00 \\
\hline Karonie & Mafics & Australia & 171 & 24.56 & 71.35 & 3.51 & 0.58 \\
\hline Wandagee & Monchiquite & Australia & 135 & 2.96 & 91.85 & 5.19 & 0.00 \\
\hline Total & samples & & 6130 & & & & \\
\hline
\end{tabular}




\section{Shape Classification for Chromites from Diamond Bearing Kimberlites and Lamproites}
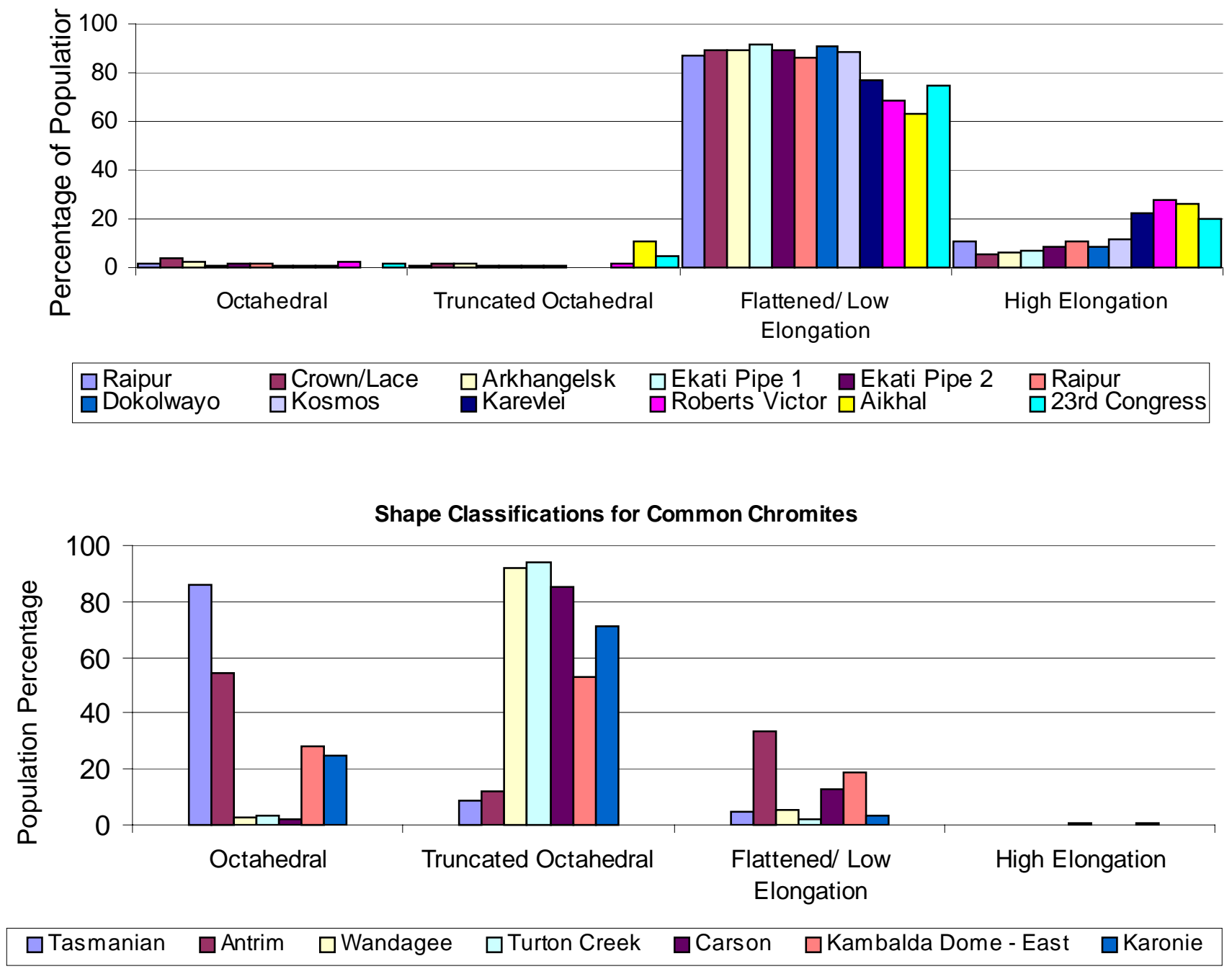

Figure 2: Histogram showing the population percentages of chromites classified according to the four classes.

\section{PLASTIC DEFORMATION IN CHROMITES}

The high proportion of distorted and elongate chromite crystals found in diamond bearing kimberlites and lamproites is almost certainly a result of plastic deformation. Plastic deformation in diamonds is believed to be caused by shearing in the asthenosphere or stress during kimberlite precursor events and conduit formation (Robinson, 1986). Deformation in diamonds has been documented from kimberlites in many localities around the world and it is probable that all natural diamond populations contain a proportion with plastic deformation (J.W.Harris, University of Glasgow, pers. comm., 2003). Evidence of plastic deformation has also been seen in olivine crystals from mantle nodules (Boullier \& Nicholas, 1975) the crystals being flattened and elongated with kink-banding perpendicular to the plane of flattening. The processes that cause plastic deformation in diamond and olivine must equally affect any co-existing chromites provided that the chromite structure is capable of deforming without fracturing.

Experimental work (Dupas-Bruzek, 1998) has shown that the spinel structure will deform by dislocation creep under high temperatures and pressures and that the spinel structure is approximately three times more resistant to creep than olivine. Polished cross sections of some of the elongated chromites have revealed only uniform internal structures and no evidence of distorted growth banding was found. Examination of chromite fragments by TEM showed only normal octahedral chromite structures with no evidence of lattice distortion. This suggests that deformation has probably occurred by stress-creep annealing and that 
mobility of elements within the lattice has destroyed any growth banding that may have been present. Recrystallisation of olivine after deformation has been observed in peridotite nodules from kimberlite (Boullier \& Nicholas, 1975) and it is probable that deformed chromites would also undergo re-crystallisation.

The possibility that growth conditions or twinning lead to the high proportion of distorted chromite crystals from kimberlites was considered. Sunagawa (1987) discusses elongation of crystals caused by twinning but there is no evidence of twinning in the flattened and elongate chromites from kimberlite and lamproite.

\section{RESORPTION AND SURFACE FEATURES}

Chromites from kimberlite and lamproite frequently have a lustrous metallic sheen caused by light reflecting from very fine stepping on resorption surfaces. This is the result of dissolution proceeding from the coigns, progressively benching back towards the centre of the octahedral faces in a series of finely spaced equal steps (Figure 3). Some areas in the centre of the octahedral faces may be unaffected by the resorption and retain a high polished luster. The dissolution process takes place under conditions where chemical attack is effective on sharp edges but not on flat surfaces. The result is a chromite with distinctive appearance. Chromites with these surface features are particularly common in the Ellendale lamproites but also occur frequently in kimberlites. In some kimberlites, resorption of chromites has proceeded further and all traces of crystal faces have been removed. The chromites may then be irregular forms but the original shape in the above classification scheme can often still be discerned as the overall shape remains equant, flattened or elongate. The surfaces may develop a chemical polish post resorption or remain etched and finely pitted.

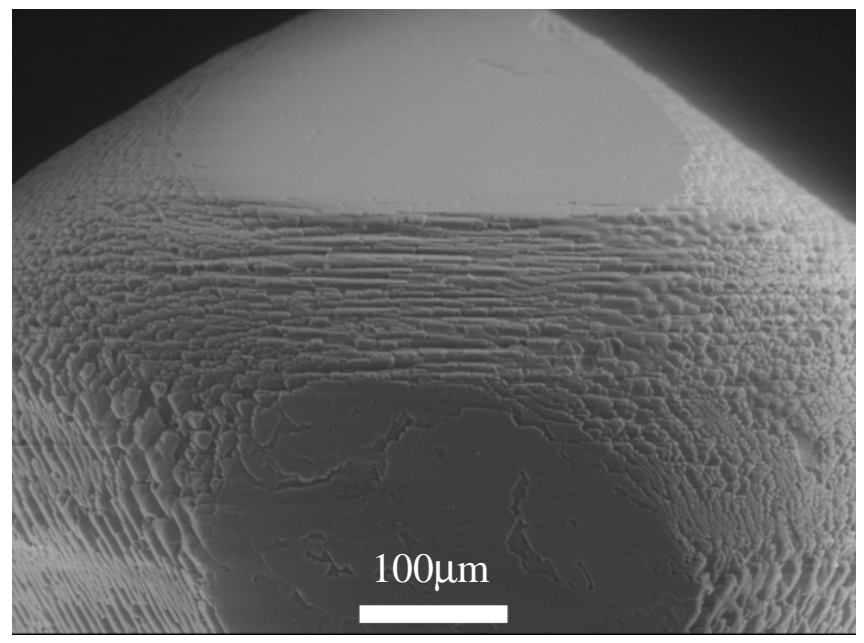

Figure 3: SEM photomicrograph of an Ellendale chromite showing a flat face adjoining a stepped edge.
Chromites from the majority of the samples from common rock types have no resorption or only minor amounts on the coigns. Some of the chromites from Tasmanian peridotites have resorption that has produced a fine matt texture on coigns and occasionally on faces. The crystallographic resorption producing fine stepped surfaces on chromites from kimberlite and lamproite is absent from most common chromites but it does occur in a limited form on some chromites from the Antrim basalts of northern Australia

\section{THE EFFECTS OF WEATHERING AND ABRASION ON CHROMITES}

Chromite is highly resistant to chemical weathering and abrasion and forms long dispersion trails from a source (Atkinson, 1986). During stream transport the surface features are abraded but the resorption features such as fine stepping on coigns and remnant crystal faces that are typical of chromites from kimberlite and lamproite may still be visible on grains that have been carried by streams for more than $20 \mathrm{~km}$ from source (D.C.Lee, unpublished data). In glaciated terrain chromites can be found at much greater distances from source with both abraded and pristine surfaces due to either mechanical abrasion in till or, alternatively being carried enclosed within rock fragments (Golubev et al., 1995). If abrasion is extensive the chromites become sub-rounded and all traces of the original surfaces may be removed but the original shape will still influence the shape of the sub-rounded remnant. It is therefore possible to examine chromites that have been subjected to extensive abrasion by stream transport or glaciation and see from the remaining morphology that the original grains were octahedral, truncated octahedral or elongated octahedral forms. Weathering of chromites under tropical conditions that cause lateritisation or in the acid environment of black soils can alter the chemistry of chromites and the internal structure breaks down until the mineral becomes fragile and disintegrates. Under these conditions $\mathrm{MgO}$ may leach from the chromite and be replaced by $\mathrm{FeO}$ during the early stages. Prior to final disintegration, the shape of a highly weathered chromite will usually be either equi dimensional, rounded with some truncation or elongate depending on its earlier shape (D C Lee, unpublished data).

\section{CHROMITE CHEMISTRY}

The chemistry of chromites derived from kimberlites has been described in terms of major elements (Mitchell, 1986) and minor elements (Griffin, 1995) and many others. The major element chemistry of chromites has not provided a sufficiently accurate method for discriminating between common chromites and those derived from kimberlite as 
there is a wide overlap of chromite compositions (Fipke et al., 1995). Afanasiev et al. (1998) describe the problems encountered by diamond explorers in Russia with high $\mathrm{Cr}_{2} \mathrm{O}_{3}$ chromites emanating from non-kimberlitic source rocks and this problem has occurred regularly in other parts of the world (D.C.Lee, unpublished data). The use of minor and trace element compositions in chromites provides a better discriminator in some cases but the techniques for analysis are expensive and not appropriate for use on the many thousands of chromites that are found during typical diamond exploration programs. In addition to the problem of overlapping chemical compositions, the chemical analysis that is obtained by electron probe analysis of a chromite can have marked variations depending on which point is analyzed in a polished cross section, the amount of metasomatism the grain has undergone and the amount of chemical weathering the grain has been subjected to.

\section{DISCUSSION}

Diamond exploration mineralogists are frequently required to make decisions about chromites that are found in exploration samples. The morphology classifications presented in Table 1 show very clearly that chromite morphology provides a powerful tool for discriminating between common chromites and chromites associated with diamonds. The minimum temperatures and pressures necessary for plastic deformation of chromites has not been determined. It is likely that some deformation may occur at lower temperatures and pressures than are required for diamond deformation and the presence of some deformed chromites in a chromite population does not imply that they are necessarily associated with diamonds. The complete absence of deformed chromites in a chromite population does, however, strongly suggest that they are not from a diamond bearing kimberlite or lamproite. In the chromite samples from Tasmania, a small proportion are flattened and elongated and chromites with similar morphology occur in some alkali basalts in N.S.W. This suggests that a small proportion of the material in these source rocks has been derived from depths where temperature and pressure is sufficient to cause a small degree of plastic deformation in chromites. The sample of chromites from the Wandagee monchiquite in Western Australia contains a few weakly deformed chromites.

The chromite populations in kimberlites and lamproites are a mixture that may include contributions from many rock types and a sharp boundary between common chromites and those from diamond bearing kimberlites and lamproites in unlikely. It is therefore necessary to examine a suite of chromites, e.g. 30 grains, when looking for evidence of plastic deformation in a chromite population.

\section{REFERENCES}

Afanasiev, V.P., Pokhilenko, N.P., Logvinova, A.M. and Yefimova, E.S., 1998. Problem of false indicators for kimberlites and lamproites (on the example of chromites). Proc. 7th Int. Kimb. Conf., Ext. Abs., Capetown, South Africa. pp. 7.

Atkinson, W.J., 1986. Diamond exploration philosophy, practice, and promises: a review. In: Kimberlites and Related Rocks (2). GSA Special Publication No 14, Blackwell, Australia, pp. 1075 - 1107.

Boullier A.M., Nicholas A., 1975. Classification of Textures and Fabrics of Peridotite Xenoliths from South African Kimberlites. In: Ahrens, Dawson, Duncan and Erlank (Eds.), Physics and Chemistry of the Earth (9). Pergammon Press, International, pp. 467 475.

Dupas-Bruzek, C., Tingle, T.N., Green II, H.W., Doukhan, N. and Doukhan, J-C., 1998. The rheology of olivine and spinel magnesium germanate $(\mathrm{Mg} 2 \mathrm{GeO} 4)$ : TEM study of the defect microstructures. Phys. Chem. Miner., 25, $501-514$.

Fipke, C.E., Gurney, J.J., Moore, J.J., 1995. Diamond Exploration Techniques Emphasising Indicator Mineral Geochemistry and Canadian Examples. Geological Survey of Canada (423). Ottawa, ON, Canada.

Griffin, W.L., Ryan, C.G., 1995. Trace elements in indicator minerals: area selection and target evaluation in diamond exploration. Jour. Geochem. Exp., 53: 311-337.

Gobulev, Y.K., 1995. Diamond Exploration in glaciated terrain; a Russian perspective. Jour. Geochem. Expl., 55, 265275.

Mitchell, R.H., 1986. Kimberlites Mineralogy, Geochemistry, and Petrology. Plenum press, New York.

Robinson D.N., Scott J.A., Van Niekirk, A., Anderson V.G., 1986. The sequence of events reflected in the diamonds of some southern African kimberlites. In: Kimberlites and Related Rocks (2). GSA Special Publication No 14, Blackwell, Australia, pp. 990 1000 .

Sunagawa, I., 1987. Morphology of minerals. In: Sunagawa I. (Editor), Morphology of Crystals, Part B, Terra Sci. Pub., Tokyo. pp. $511-587$.

Contact: DC Lee, 117 Lissadell Street, Floreat, Western

Australia, 6014, E-mail: Dearn@bigpond.com.au 